УДК 616.12-009.72+611.018.74]-085

DOI: $10.26435 /$ UC.V0I2(35).441

\author{
Е.А. Контовский, Е.Н. Кошелева, А.В. Дубовик, Ю.О. Брыжатая
}

ГОО ВПО «Донецкий национальный медицинский университет имени М. Горького», Донецк

\title{
КОРРЕКЦИЯ ЭНДОТЕЛИАЛЬНОЙ ДИСФУНКЦИИ У БОЛЬНЫХ С МИКРОСОСУДИСТОЙ СТЕНОКАРДИЕЙ
}

\section{ЦЕЛЬ РАБОТЫ}

Исследование заключалось в анализе влияния интервальной нормобарической гипокситерапии на маркеры эндотелиальной дисфункции у больных микрососудистой стенокардией.

Эндотелий - однослойный пласт плоских клеток, выстилающих внутреннюю поверхность кровеносных и лимфатических сосудов, а также камер сердца. До недавнего времени считалось, что главная функция эндотелия - это «полировка» сосудов изнутри. В 1980-х гг. это мнение изменилось, и стало ясно, что эндотелий является не только монослоем, который служит физическим барьером между кровью и подлежащей тканью, но также действует как эндокринный орган, способный вырабатывать и выделять различные метаболически активные вещества. Поэтому термином «функция эндотелия», или «эндотелиальная функция» обозначают способность эндотелиоцитов участвовать в выработке широкого спектра вазоактивных веществ. Термин «эндотелиальная дисфункция» был введен в обиход в середине 80-х годов после крупного прорыва, сделанного R.F. Furchgott и J.V. Zawadzki. Авторы обнаружили способность изолированной артерии к самостоятельному изменению своего мышечного тонуса в ответ на ацетилхолин без участия центральных (нейрогуморальных) механизмов. Главная заслуга в этом отводилась эндотелиальным клеткам, которые были охарактеризованы авторами как «сердечно-сосудистый эндокринный орган, осуществляющий связь в критических ситуациях между кровью и тканями» [13].

Под понятием «эндотелиальная дисфункция» (ЭД) понимается патологическое состояние, в основном характеризуемое дисбалансом между веществами с сосудорасширяющими, антимитогенными и антитромбогенными свойствами (эндотелий-зависимые релаксирующие факторы) и веществами с сосудосуживающими, протромботическими и пролиферативными ха- рактеристиками (эндотелий-зависимые суживающие факторы) [3,13].

В конце XX века, в 1998 г., R. Furchgott, L. Ignarro и F. Murad получили Нобелевскую премию в области медицины за открытие роли оксида азота NO как сигнальной молекулы в регуляции сердечно-сосудистой системы. Авторами было установлено, что нитроглицерин и сходные лекарства действуют как вазодилататоры в результате преобразования их, с участием эндотелия, в оксид азота NO, который оказывает основное расслабляющее действие на кровеносные сосуды. Кроме того, молекулы NO ингибируют такие ключевые звенья в развитии атеросклероза, как адгезия и агрегация тромбоцитов, адгезия лейкоцитов и миграция, а также пролиферация клеток гладких мышц.

Стало ясно, что основной причиной артериальной гипертензии (АГ) и других сердечнососудистых заболеваний (ССЗ) является патология эндотелия [9].

Эндотелий играет важную роль в модуляции тонуса сосудов, синтезируя и высвобождая множество релаксирующих факторов, в том числе сосудорасширяющие простагландины, NO и фактор гиперполяризации эндотелия, а также сосудосуживающие факторы [13, 22]. Оксид азота, простациклин и фактор гиперполяризации эндотелия являются также потенциальными ингибиторами функции тромбоцитов и пролиферации гладкомышечных клеток (ГМК) сосудов $[13,14]$. Также эндотелиоциты синтезируют субстанции, важные для контроля свертывания крови, регуляции сосудистого тонуса, артериального давления, фильтрационной функции почек, сократительной активности сердца, метаболического обеспечения мозга. Эндотелий способен реагировать на механическое воздействие протекающей крови, величину давления

(c) Е.А. Контовский, Е.Н. Кошелева, А.В. Дубовик, Ю.О. Брыжатая, 2020

(c) Университетская Клиника, 2020 
крови в просвете сосуда и степень напряжения мышечного слоя сосуда. Клетки эндотелия чувствительны к химическим воздействиям, которые могут приводить к повышенной агрегации и адгезии циркулирующих клеток крови, развитию тромбоза, оседанию липидных конгломератов. ЭД в основном вызвана снижением производства или действия релаксирующих факторов, вызванных эндотелием, и может стать первым шагом к СС3 [4].

В основе патогенеза микрососудистой стенокардии лежит длительный спазм дистальных веточек коронарных артерий. Сегодня доминирует гипотеза о том, что в основе микроваскулярной стенокардии лежат процессы эндотелиальной дисфункции с угнетением продукции эндотелиальных вазодилататоров, в первую очередь оксида азота. Преобладание вазоконстриктивных веществ приводит к транзиторному спазму мелких ветвей венечных артерий [3].

Место спазма может локализоваться в различных сегментах коронарного русла по отдельности или в нескольких одновременно. Правая коронарная артерия является наиболее часто поражаемым сосудом, передняя нисходящая артерия является второй по частоте встречаемости [14]. В некоторых случаях коронарные артерии, подвергнувшиеся вазоспазму, поражены атеросклеротическими бляшками, а иногда абсолютно интактны, что, вероятно, влияет на прогноз заболевания. Ряд исследований подтверждает более высокий риск осложнений при атеросклеротическом поражении сосудов [23,24]. Однако из ряда других исследований [26,29,30] известно, что пациенты без гемодинамически значимых стенозов характеризуются худшим прогнозом. Это объясняется отсутствием коллатералей и метаболической адаптации миокарда к ишемии.

При микрососудистой стенокардии проводят коронарографию с провокационными пробами. К ним относятся фармакологические пробы с интракоронарным введением ацетилхолина или алкалоидов спорыньи (эргоновина, эргометрина или метилэргометрина), а также холодовая и гипервентиляционная проба. Последние не всегда информативны, а фармакологические пробы сопряжены с высоким риском осложнений, что ограничивает их применение. Также в дифференциальной диагностике может помочь перфузионная сцинтиграфия миокарда, которая точно определяет нарушения микроциркуляции на фоне сохраненного кровотока в коронарных артериях [20].

У 10-20\% пациентов, которым проводили коронарную ангиографию по причине острого или хронического ишемического синдрома, коронарные артерии интактны. У таких пациентов часто диагностируют «микрососудистую стенокардию» (MC) [4]. Несмотря на относительную безопасность микрососудистой стенокардии и достаточно благоприятный прогноз, качество жизни пациентов остается крайне неудовлетворительным [8].

Эндотелиальные клетки, вследствие своего уникального положения на границе между циркулирующей кровью и тканями, отличаются особенной уязвимостью при действии разнообразных патогенных факторов, находящихся в системном и местном кровотоке. Именно эндотелиоциты первыми встречаются с продуктами обмена веществ, свободными радикалами, тяжелыми металлами и лекарственными препаратами, которые вызывают повреждение внутренней выстилки сосудов [8].

В соответствии с современными представлениями одним из ключевых патогенетических механизмов многих заболеваний является эндотелиальная дисфункция - прогрессирующее нарушение структуры и функции эндотелия, характеризующееся дисбалансом между факторами, обеспечивающими местные процессы регуляции тонуса сосудов, гемостаза, пролиферации и миграции клеток крови в сосудистую стенку [21].

Эндотелиальные факторы, секретируемые эндотелием, играют важную роль в регуляции функциональной активности, пролиферации и апоптоза клеток сосудистой стенки, его взаимодействии с образующимися элементами и компонентами плазмы крови, регуляции тонуса сосудов, формировании атером и процессов образования тромба $[4,14]$.

Одним из мощных факторов, модулирующих метаболизм эндотелиоцитов, является гипоксия [9]. Прерывистые эффекты гипоксии используются для своеобразной «тренировки», активации процессов коронарной артериальной дилатации и уменьшения спазма субэндокардиальных артерий и возникающей в результате ишемии [11].

Под влиянием интервальной нормобарической гипокситерапии (ИНБГТ) развивается комплекс адаптационных изменений в различных системах организма, в том числе увеличение потребления и эффективности использования кислорода, увеличение кислородной емкости крови и снижение реактивности симпатоадреналовой системы [13, 14,17].

\section{МАТЕРИАЛ И МЕТОДЫ}

Обследовано 76 больных с микрососудистой стенокардией (32 мужчины и 44 женщины), из этого количества было исключено 18 человек (10 мужчин и 8 женщин), которые не прошли кри- 


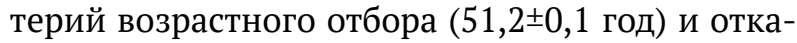
зались от дальнейшей терапии. В итоге основная, контрольная группа обследуемых составила 58 больных микрососудистой стенокардией, среди которых мужчин - 22 (38,0\%), женщин 36 (62,0\%). Протокол исследования одобрен локальным этическим комитетом.

Диагностика микрососудистой стенокардии базировалась на анализе типичности приступов стенокардии с депрессией сегмента ST $\geqslant 1,5$ мм [0,15 мВ] продолжительностью более 1 минуты, установленной при 48-часовом мониторировании ЭКГ при условии отсутствия атеросклероза коронарных артерий и спазма эпикардиальных венечных артерий на коронарографии [30]. Признаками, указывающими на наличие микрососудистой стенокардии, были: симптом «задержки» контрастного вещества, наличие «миокардальных мостиков», извитость сосудов или неровность их контуров [25].

Методом случайной выборки пациенты распределены в две группы наблюдения, которые не различались между собой по возрасту, полу, клинической картине приступов стенокардии, результатам коронарографии и холтеровского мониторирования ЭКГ, т.е. были сопоставимыми. Пациенты 1-ой группы получали только медикаментозноелечение (бета-адреноблокаторы, статины, ингибиторы ангиотензинпревращающего фермента, антагонисты кальция, нитраты, триметазидин), а пациенты 2-ой - дополнительно к медикаментозной терапии - сеансы интервальной нормобарической гипокситерапии. В группу контроля включены 25 практически здоровых людей, которые не различались по полу и возрасту с группами наблюдения. Эта группа была подобрана для более четкой верификации и достоверности клинических изменений у больных с микрососудистой стенокардией как первой, так и второй группы. Группы больных и здоровых не различались по возрасту, полу, длительности МC $\left(\chi^{2}=0,18, \mathrm{p}=0,69 ; \chi^{2}=0,34\right.$, $\mathrm{p}=0,50 ; \chi^{2}=0,87, \mathrm{p}=0,21$ соответственно).

Изменения продукции эндотелиальных факторов при микрососудистой стенокардии под воздействием переменной гипоксии позволяли предполагать участие эндотелия в механизмах ответа на интервальную нормобарическую гипокситерапию, в связи с чем в крови больных и здоровых до и после лечения (наблюдения) определяли содержание васкулярного эндотелиального фактора роста - vascularendothelialgrowthfactor (VEGF), «большого» эндотелина-1 (ЭТ-1) 1-38 (маркеры активации/повреждения эндотелиоцитов) и CD31+ эндотелиальных микрочастиц (ЭМ) (маркер регенерации эндотелия). Концентрацию в сыворотке крови васку- лярного эндотелиального фактора роста и большого ЭТ-1 1-38 определяли методом иммуноферментного анализа. Концентрацию эндотелиальных микрочастиц определяли в бедной тромбоцитами плазме крови подсчетом CD31+ частиц размером 1,5-4,0 мкм методом проточной цитофлуорометрии с использованием мышиных моноклональных ФИТЦ-меченых антител фирмы «Coltag» (США) с использованием цитофлуориметра «ЕpixXL» фирмы «Coulter» (Франция).

Конъюнктивальную микроскопию проводили с помощью щелевой лампы ЩЛ-2 (Россия), установленной горизонтально на подвижном штативе (16-кратное увеличение). Этот метод максимально доступен и наиболее информативен, без побочных эффектов, отображает нарушения кровообращения переднего отдела глазного яблока и его изменения, на которых базируются исследования биомикроскопии - нарушение продукции эндотелиальных факторов при микрососудистых изменениях позволяли выявить участие эндотелия в механизмах ответа на интервальную нормобарическую гипокситерапию. Оценку микроциркуляции проводили по методу В.С. Волкова и соавторов (1976) с вычислением конъюнктивального индекса - суммы баллов (условных единиц) признаков нарушения микроциркуляции.

Курс интервальной нормобарической гипокситерапии, который проводили с использованием установки «ГИП 10-1000-0» (Россия), включал 20 ежедневных сеансов продолжительностью по 60 минут каждый. Вначале проводили пробный сеанс для определения чувствительности к гипоксии. При удовлетворительных результатах начинали ежедневные сеансы, состоящие из 6 циклов длительностью по 10 минут, в которых вдыхание через маску гипоксической газовой смеси с содержанием кислорода 10-12\% чередовалось с вдыханием атмосферного воздуха в циклическом режиме. Длительность вдыхания гипоксической смеси в цикле увеличивали от 1 до 5 минут в первые четыре дня курса, а затем она составляла 5 минут. Продолжительность процедуры определяли, исходя из значений пробы Штанге - продолжительности задержки дыхания на вдохе.

Статистическая обработка фактического материала проведена при помощи компьютерной программы «Statistica 6.0» с подсчетом параметрических и непараметрических критериев (критерий Стьюдента для зависимых и независимых выборок и $\chi^{2}$ ). Основными критериями подбора больных являлись следующие: это возрастной отбор - 51,2 $\pm 0,1$ года, в связи с наиболее характерными для этого возраста проявлени- 
ями микрососудистых нарушений коронарного кровообращения; также анализ типичности приступов стенокардии с депрессией сегмента $\mathrm{ST} \geqslant 1,5 \mathrm{Mm}[0,15 \mathrm{MB}]$ продолжительностью более 1 минуты, установленной при 48-часовом мониторировании ЭКГ с учетом отсутствия атеросклероза коронарных артерий и спазма эпикардиальных венечных артерий на коронарографии [20], а также признаки, подтверждающие наличие микрососудистой стенокардии: симптом «задержки» контрастного вещества, наличие «миокардальных мостиков», извитость сосудов или неровность их контуров [25]. Наличие статистически значимых различий считали при уровне значимости $<0,05$.

\section{РЕЗУЛЬТАТЫ И ОБСУЖДЕНИЕ}

В таблице 1 представлена динамика факторов повреждения и защиты эндотелия у больных микрососудистой стенокардией как при использовании медикаментозной терапии, так и при ее отсутствии. В таблице 2 представлена динамика с использованием как медикаментозной терапии, так и сеансов интервальной нормобарической гипокситерапии. Исходные величины васкулярного эндотелиального фактора роста у больных микрососудистой стенокардией были двукратно повышены по сравнению со здоровыми. Так же оказалась увеличенной концентрация ЭТ-1. Напротив, величина эндотелиальных микрочастиц (ЭМ) в начале наблюдения была сниженной. Представленные данные сви- детельствуют о формировании эндотелиальной дисфункции. При этом факторы сосудистого повреждения (VEGF и ЭT-1) и снижение защиты (ЭМ) в полной мере отражают преобладание альтеративных (вазоконстрикторных) процессов над процессами регенерации сосудистого эндотелия и вазодилатации.

Лечение у пациентов 1-ой группы с использованием набора лекарственных средств не оказывало влияния на величину изучаемых факторов сосудистого повреждения/регенерации. Только при повторном исследовании у пациентов 2-ой группы отмечено статистически достоверное снижение васкулярного эндотелиального фактора роста и, очевидно, компенсаторное (стимулированное) увеличение ЭМ, который является отражением процессов ангиодилатации. Нельзя исключить, что повышение плазменного уровня ЭМ связано с усилением их образования при так называемой активации эндотелиоцитов, которая рассматривается как адаптивная реакция клеток на возмущающие факторы и проявляется комплексом фенотипических изменений при отсутствии морфологических признаков повреждения. Нельзя не учитывать, что исходное увеличение концентрации васкулярного эндотелиального фактора роста на фоне интервальной нормобарической гипокситерапии и лекарственной терапии (2-я группа) обусловлено активными формами кислорода, высвобождающегося при активации повреждения эндотелиоцитов [20].

Динамика в первой группе: ЭМ (109/л), ЭТ-1 1-38 (10-12/л), VEGF (10-7/л) у боль-

Таблица 1. ных микрососудистой стенокардией и у здоровых людей

\begin{tabular}{cccc}
\hline \multirow{2}{*}{$\begin{array}{c}\text { Динамика факторов повреждения } \\
\text { и защиты эндотелия }\end{array}$} & \multicolumn{3}{c}{1 До группа } \\
\cline { 2 - 4 } & $0,7 \pm 0,03^{*}$ & После лечения & 3доровые \\
\hline \hline ЭМ & $1,9 \pm 0,04^{*}$ & $0,7 \pm 0,06^{*}$ & $2,1 \pm 0,08$ \\
\hline ЭТ-1 1-38 & $2,4 \pm 0,1^{*}$ & $1,8 \pm 0,05^{*}$ & $1,5 \pm 0,04$ \\
\hline VEGF & $2,4 \pm 0,09^{*}$ & $1,2 \pm 0,05$ \\
\hline
\end{tabular}

Примечание: * - различия между аналогичными показателями у больных и здоровых статистически достоверны.

Динамика во второй группе: ЭМ (109/л), ЭТ-1 1-38 (10-12/л), VEGF (10-7/л)

Таблица 2. у больных микрососудистой стенокардией и у здоровых людей

\begin{tabular}{|c|c|c|c|}
\hline \multirow{2}{*}{$\begin{array}{l}\text { Динамика факторов повреж- } \\
\text { дения и защиты эндотелия }\end{array}$} & \multicolumn{3}{|c|}{ 2-я группа } \\
\hline & До лечения & После лечения & Здоровые \\
\hline ЭМ & $0,7 \pm 0,05^{*}$ & $2,2 \pm 0,03 \#$ & $2,1 \pm 0,08$ \\
\hline ЭТ-1 1-38 & $1,9 \pm 0,07 *$ & $1,7 \pm 0,06^{*}$ & $1,5 \pm 0,04$ \\
\hline VEGF & $2,5 \pm 0,08^{*}$ & $1,4 \pm 0,03 \#$ & $1,2 \pm 0,05$ \\
\hline
\end{tabular}

Примечание: * - различия между аналогичными показателями у больных и здоровых статистически достоверны; \# - различия между аналогичными показателями до и после лечения статистически достоверны. 
После курса интервальной нормобарической гипокситерапии, по данным конъюнктивальной микроскопии, в микроциркуляторном русле происходило выравнивание калибра сосудов, увеличение артериоло-венулярного соотношения, уменьшение встречаемости зон «запустевания» капилляров и, как следствие, снижение конъюнктивального индекса с 2,4 до 1,3 баллов $(\mathrm{p}<0,05)$ (см. рис.).

Несмотря на то, что данный показатель уменьшался в обеих группах, в большей степени это происходило на фоне интервальной нормобарической гипокситерапии (2-я группа).

В настоящее время доказано, что одним из ведущих механизмов микрососудистой стенокардии является эндотелиальная дисфункция, которая сопровождается снижением способности артерий к вазодилатациии и преобладанием ангиоконстрикции $[4,11,23]$. Оба эти механизма клинически проявляются типичными клиническими, электрокардиографическими и эхокардиографическими изменениями.

Другой ведущей гипотезой патогенеза микрососудистой стенокардии является гипотеза о функциональных нарушениях микроциркуляции в интрамускулярных (интрамуральных) преартериолах и артериолах, т.е. в сосудах, которые не могут быть визуализированы при коронароангиографии. Высказано предположение о том, что эндотелиальная дисфункция, лежащая в основе микрососудистой стенокардии, является лишь дебютом многостадийного патологического процесса [4]. С течением времени к функциональным проявлениям присоединяется органический компонент с формированием атером и запуском каскада ишемической болезни сердца [4]. В одном из исследований у боль- ных выявлена умеренная гиперхолестеринемия [13]. Авторы считают, что «наслоение» нарушений липидного обмена на «функциональный» компонент будет способствовать развитию атеросклеротического процесса. Несмотря на активное применение эндотелийактивных классов лекарственных средств, таких как ингибиторы ангиотензинпревращающего фермента (периндоприл), статины, нитраты (донаторы синтеза оксида азота), бета-адреноблокаторы, статины, антиагреганты, проблема лечения таких пациентов остается нерешенной. Эффективность монотерапии одним классом препаратов (нитраты, бета-адреноблокаторы, ингибиторы ангиотензинпревращающего фермента) колеблется в пределах 19-38\%. Комбинированное лечение с использованием 2-3-х классов повышает этот показатель до 50-65\%.

Эндотелиальная дисфункция является самым ранним звеном в развитии атеросклероза, она определяется уже в период, предшествующий формированию атеросклеротической бляшки, до клинических проявлений болезни, а повреждение эндотелия, вызывая дисбаланс в синтезе вазоконстрикторных и вазорелаксирующих веществ, ведет к тромбообразованию, адгезии лейкоцитов и пролиферации гладкомышечных клеток в артериальной стенке [11]. Эндотелиальная дисфункция со снижением биодоступности эндотелий-зависимого фактора релаксации - оксида азота и с увеличением уровня эндотелина-1 может объяснить нарушенную микроциркуляцию при микрососудистой стенокардии. Кроме того, низкие показатели соотношения этих веществ, прямо соотносятся с выраженностью болевого синдрома у этих больных [4].

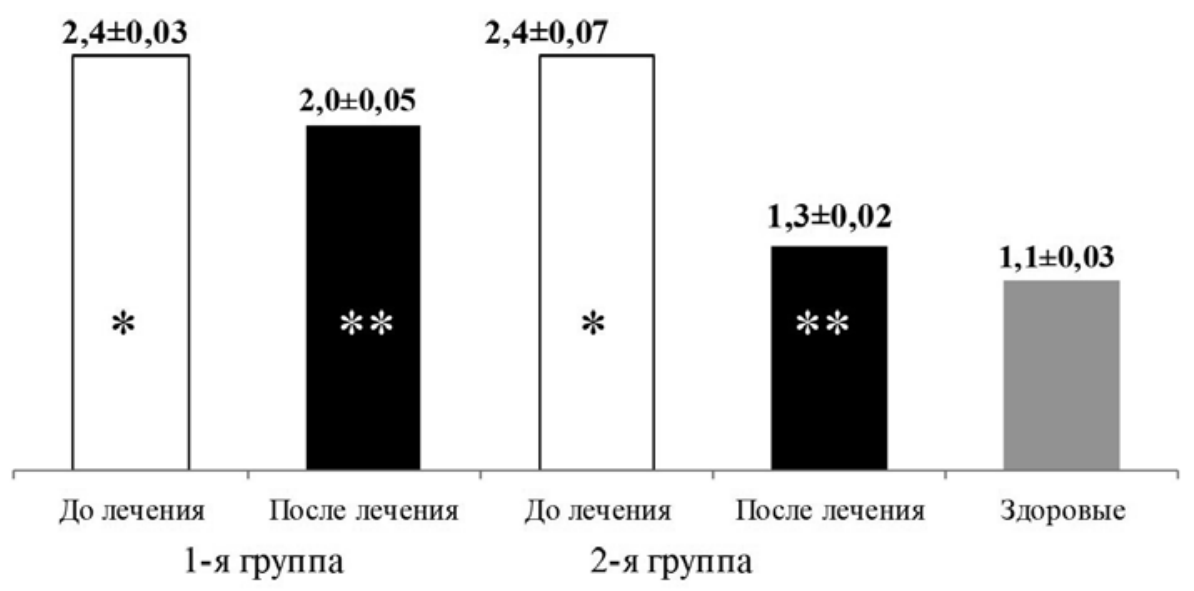

Рис. Динамика конъюнктивального индекса у больных микрососудистой стенокардией до и после лечения, а также у здоровых, $(\mathrm{M} \pm \mathrm{m}$, баллов $)$; - различия между аналогичными показателями у больных и здоровых, статистически достоверны; ** - различия между аналогичными показателями до и после лечения статистически достоверны. 


\section{З АКЛЮ Ч Н ИЕ}

Одним из основных механизмов спазма мелких ветвей коронарных артерий при микрососудистой стенокардии является дисфункция эндотелия, которая проявляется в несоответствии сосудистых факторов, отражающих процесс повреждения и регенерации сосудистого эндотелия. Включение интервальной нормобарической гипокситерапии в комплекс лечебных мероприятий помогает уменьшить выраженность артериального спазма. В то же время такая гипотеза должна быть клинически проверена и нуждается в предоставлении подробной доказательной базы. Медикаментозная терапия оказала положительное влияние на конъюнктивальную микроскопию, хотя наилучшие результаты были достигнуты при сочетании медикаментозного лечения с интервальной нормобарической гипокситерапией.

\section{Е.А. Контовский, Е.Н. Кочелева, А.В. Дубовик, Ю.О. Брыжатая}

ГОО ВПО «Донецкий национальный медицинский университет имени М. Горького», Донецк

\section{КОРРЕКЦИЯ ЭНДОТЕЛИАЛЬНОЙ ДИСФУНКЦИИ У БОЛЬНЫХ С МИКРОСОСУДИСТОЙ СТЕНОКАРДИЕЙ}

В статье проведен анализ воздействия интервальной нормобарической гипокситерапии на функцию эндотелия сосудов у пациентов с микрососудистой стенокардией. Результаты исследования показали, что эндотелиальная дисфункция является ведущим механизмом спазма мелких ветвей коронарных артерий. Включение гипокситерапии в комплекс лечебных мероприятий способствует восстановлению про- цессов регенерации эндотелия артерий и отвечает положительной динамикой на показатели микроциркуляции коронарных артерий.

Ключевые слова: микрососудистая стенокардия, эндотелиальные факторы, интервальная нормобарическая гипокситерапия, коронарография, эндотелиальная дисфункция.

\section{E.A. Kontovskiy, E.N. Kosheleva, A.V. Dubovik, U.O. Bryzhataya}

SEI HPE «M. Gorky Donetsk National Medical University», Donetsk

\section{CORRECTION OF ENDOTHELIAL DYSFUNCTION IN PATIENTS WITH MICROVASCULAR ANGINA PECTORIS}

The article presents an analysis of the effect of interval normobaric hypoxic therapy on vascular endothelial function in patients with microvascular angina pectoris. The results of the study showed that the leading mechanism of spasm of small branches of the coronary arteries is endothelial dysfunction. The inclusion of hypoxytherapy in the complex of therapeutic measures contributes to the activation of the processes of endothelial regeneration of the arteries and positively affects the microcirculation.

Key words: microvascular angina, endothelial factors, interval normobaric hypoxytherapy, coronarography, endothelial dysfunction.

\section{ЛИТЕРАТУРА}

1. Афонасьева Т.Н. Эндотелиальная дисфункция. Возможности ранней диагностики: Здоровье и образование в XXI веке. 2016; 18: 101-104.

2. Васина Л.В., Петрищев Н.Н., Власов Т.Д. Эндотелиальная дисфункция и ее основные маркеры: Регионарное кровообращение и микроциркуляция. 2017; 16: 4-15.

3. Вермель А. Е. Кардиальный синдром Х. Клин. мед. 2006; 6: 5-9.

4. Ельчанинова С.А., Кореняк Н.А., Дрягина И.В. и др. Маркеры повреждения эндотелия как возможный критерий эффективности лечения артериальной гипертензии. Клин. лаб. диаг. 2007; 2: 40-42.

5. Иванов А.Н., Гречихин А.А., Норкин И.А., Пучиньян Д.М. Методы диагностики эндотелиальной дисфункции. Регионарное кровообращение и микроциркуляция. 2014; 13: 4-11.

\section{REFERENCES}

1. Afonas'eva T.N. Endotelial'naya disfunktsiya. Vozmozhnosti rannei diagnostiki: Zdorov'e i obrazovanie $\mathrm{v}$ XXI veke. 2016; 18: 101-104 (in Russian).

2. Vasina L.V., Petrishchev N.N., Vlasov T.D. Endotelial'naya disfunktsiya i ee osnovnye markery: Regionarnoe krovoobrashchenie i mikrotsirkulyatsiya. 2017; 16: 4-15 (in Russian).

3. Vermel' A. E. Kardial'nyi sindrom X. Klin. med. 2006; 6: 5-9 (in Russian).

4. El'chaninova S.A., Korenyak N.A., Dryagina I.V. i dr. Markery povrezhdeniya endoteliya kak vozmozhnyi kriterii effektivnosti lecheniya arterial'noi gipertenzii. Klin. lab. diag. 2007; 2: 40-42 (in Russian).

5. Ivanov A.N., Grechikhin A.A., Norkin I.A., Puchin’yan D.M. Metody diagnostiki endotelial'noi disfunktsii. Regionarnoe krovoobrashchenie i mikrotsirkulyatsiya. 2014; 
6. Карпов Ю.А., Булкина О.С., Лопухова В.В. и др. Диагностика и терапия вазоспастической стенокардии в эпоху инвазивного лечения ИБС: описание клинических случаев. РМЖ. 2014; 23: 27-31.

7. Лысенко М.Э. Функциональное состояние эндотелия и особенности липидного спектра крови при ишемической болезни сердца. Укр. тер. журн. 2006; 2: 21-24.

8. Лупанов В.П. Алгоритм диагностики и лечения больных с болью в грудной клетке и нормальной коронарной ангиограммой (коронарным синдромом X). Русский мед. журнал. 2005; 14: 939-943.

9. Макаренко В.В., Дрягина И.В., Кореняк Н.А. Эндотелины как маркеры повреждения эндотелия. Молодежь Барнаула: материалы VII научно-практической конференции молодых ученых. Барнаул; 2005: 190-191.

10. Пизов А.В., Скачкова О.А., Пизова Н.В. Эндотелиальная функция в норме и при патологии: Медицинский совет. $2019 ; 6:$ 154-159.

11. Рустамова Я. К., Алехин М.Н., Сидоренко Б.А., Азизов В.А. Патогенез, клиника и диагностика коронарного синдрома Х. Кардиология. 2008; 11: 74-78.

12. Степанова Т.В., Иванов А.Н., Терешкина Н.Е. и др. Маркеры эндотелиальной дисфункции: патогенетическая роль и диагностическое значение. Клиническая лабораторная диагностика. 2019; 1: 34-41.

13. Телкова И.Л. Клинические и патофизиологические аспекты влияния хронической гипоксии ишемии на энергетический метаболизм миокарда. Клин. мед. 2004; 3: 4-11.

14. Телкова И. Л. Отдаленные клинические исходы коронарного синдрома X по данным 15-летнего мониторинга. Клин. медицина. 2010; 2 : 18-21.

15. Ульбашева Е.А., Намитоков А.М. и др. Варианты клинического течения вазоспастической стенокардии. Комплексные проблемы сердечно-сосудистых заболеваний. 2018; 7: 121-127.

16. Филиппов Е.В. Возможности коррекции эндотелиальной дисфункции у пациентов с артериальной гипертензией и ишемической болезнью сердца. Медицинский совет. 2019; 5: 64-67.

17. Bellamy M.F., Goodfellow J., Tweddel A.C. et al. Syndrome $\mathrm{X}$ an endothelial dysfunction. Cardiovasc. Res. 1998; 40: 410-417.

18. Bonow R.O., Mann D.L., Zipes D.P. et al. Braunwald's heart disease: a textbook of cardiovascular medicine: 10th ed. Elsevier; 2015. 1943.

19. Buda V., Andor M., Petrescu L. et al. Perindopril Induces TSP-1 Expression in Hypertensive Patients with Endothelial Dysfunction in Chronic Treatment. Int J Mol Sci. 2017; 18: 348-359.

20. Elchaninova S.A., Korenyak N.A., Kalachev A.G. et al. Mechanisms of the adaptation to intermittent normobaric hypoxia in patiens with arterial hypertension: International society for adaptive medicine VIII world congress. Moscow; 2006: 200-200.

21. Graf S., Khorsand A., Gwechenberger M. et al. Typical chest pain and normal coronary angiogram: cardiac risk factor analysis versus PET for detection of microvascular disease. J. Nucl. Med. 2007; 48 (2): 175-181.

22. Peller M., Ozierański K., Balsam P. et al. Influence of betablockers on endothelial function: A meta-analysis of randomized controlled trials. Cardiol J. 2015; 22: 708-716.

23. Takagi Y., Takahashi J., Yasuda S., Miyata S., Tsunoda R., Ogata Y. et al. Prognostic stratification of patients with vasospastic angina. JACC. 2013; 62: 1144-1153.

24. Takase S., Matoba T., Nakashiro S. et al. Ezetimibe in Combination With Statins Ameliorates Endothelial Dysfunction in Coronary Arteries After Stenting: The CuVIC Trial (Effect of Cholesterol Absorption Inhibitor Usage on Target Vessel Dysfunction After Coronary Stenting), a Multicenter Randomized Controlled Trial. Arterioscler Thromb Vasc Biol. 2017; 37: 350-358.

25. Yurdagul A. Jr., Finney A.C., Woolard M.D., Orr A.W. The arterial microenvironment: the where and why of atherosclerosis: Biochem J. 2017; 473 (10): 1281-1295.
13: 4-11 (in Russian).

6. Karpov Yu.A., Bulkina O.S., Lopukhova V.V. i dr. Diagnostika i terapiya vazospasticheskoi stenokardii v epokhu invazivnogo lecheniya IBS: opisanie klinicheskikh sluchaev. RMZh. 2014; 23: 27-31 (in Russian).

7. Lysenko M.E. Funktsional'noe sostoyanie endoteliya i osobennosti lipidnogo spektra krovi pri ishemicheskoi bolezni serdtsa. Ukr. ter. zhurn. 2006; 2: 21-24 (in Russian).

8. Lupanov V.P. Algoritm diagnostiki i lecheniya bol'nykh $\mathrm{s}$ bol'yu v grudnoi kletke i normal'noi koronarnoi angiogrammoi (koronarnym sindromom Kh). Russkii med. zhurnal. 2005; 14: 939-943.

9. Makarenko V.V., Dryagina I.V., Korenyak N.A. Endoteliny kak markery povrezhdeniya endoteliya. Molodezh' Barnaula: materialy VII nauchno-prakticheskoi konferentsii molodykh uchenykh. Barnaul; 2005: 190-191.

10. Pizov A.V., Skachkova O.A., Pizova N.V. Endotelial'naya funktsiya v norme i pri patologii: Meditsinskii sovet. 2019; 6: 154-159 (in Russian).

11. Rustamova Ya. K., Alekhin M.N., Sidorenko B.A., Azizov V.A. Patogenez, klinika i diagnostika koronarnogo sindroma X. Kardiologiya. 2008; 11: 74-78 (in Russian).

12. Stepanova T.V., Ivanov A.N., Tereshkina N.E. i dr. Markery endotelial'noi disfunktsii: patogeneticheskaya rol' i diagnosticheskoe znachenie. Klinicheskaya laboratornaya diagnostika. 2019; 1: 34-41 (in Russian).

13. Telkova I.L. Klinicheskie i patofiziologicheskie aspekty vliyaniya khronicheskoi gipoksii ishemii na energeticheskii metabolizm miokarda. Klin. med. 2004; 3: 4-11 (in Russian).

14. Telkova I. L. Otdalennye klinicheskie iskhody koronarnogo sindroma X po dannym 15-letnego monitoringa. Klin. meditsina. 2010; 2: 18-21 (in Russian).

15. Ul'basheva E.A., Namitokov A.M. i dr. Varianty klinicheskogo techeniya vazospasticheskoi stenokardii. Kompleksnye problemy serdechno-sosudistykh zabolevanii. 2018; 7: 121-127 (in Russian).

16. Filippov E.V. Vozmozhnosti korrektsii endotelial'noi disfunktsii u patsientov $\mathrm{s}$ arterial'noi gipertenziei i ishemicheskoi bolezn'yu serdtsa. Meditsinskii sovet. 2019; 5: 6467 (in Russian).

17. Bellamy M.F., Goodfellow J., Tweddel A.C. et al. Syndrome $\mathrm{X}$ an endothelial dysfunction. Cardiovasc. Res. 1998; 40: 410-417.

18. Bonow R.O., Mann D.L., Zipes D.P. et al. Braunwald's heart disease: a textbook of cardiovascular medicine: 10th ed. Elsevier; 2015. 1943.

19. Buda V., Andor M., Petrescu L. et al. Perindopril Induces TSP-1 Expression in Hypertensive Patients with Endothelial Dysfunction in Chronic Treatment. Int J Mol Sci. 2017; 18: 348-359.

20. Elchaninova S.A., Korenyak N.A., Kalachev A.G. et al. Mechanisms of the adaptation to intermittent normobaric hypoxia in patiens with arterial hypertension: International society for adaptive medicine VIII world congress. Moscow; 2006: 200-200.

21. Graf S., Khorsand A., Gwechenberger M. et al. Typical chest pain and normal coronary angiogram: cardiac risk factor analysis versus PET for detection of microvascular disease. J. Nucl. Med. 2007; 48 (2): 175-181.

22. Peller M., Ozierański K., Balsam P. et al. Influence of betablockers on endothelial function: A meta-analysis of randomized controlled trials. Cardiol J. 2015; 22: 708-716.

23. Takagi Y., Takahashi J., Yasuda S., Miyata S., Tsunoda R., Ogata Y. et al. Prognostic stratification of patients with vasospastic angina. JACC. 2013; 62: 1144-1153.

24. Takase S., Matoba T., Nakashiro S. et al. Ezetimibe in Combination With Statins Ameliorates Endothelial Dysfunction in Coronary Arteries After Stenting: The CuVIC Trial (Effect of Cholesterol Absorption Inhibitor Usage on Target Vessel Dysfunction After Coronary Stenting), a Multicenter Randomized Controlled Trial. Arterioscler Thromb Vasc Biol. 2017; 37: 350-358.

25. Yurdagul A. Jr., Finney A.C., Woolard M.D., Orr A.W. The arterial microenvironment: the where and why of atherosclerosis: Biochem J. 2017; 473 (10): 1281-1295. 